\title{
Appel aux confrères et consœurs qui posent leur candidature à l'automne pour le Conseil national ou le Conseil des Etats
}

Mesdames, Messieurs,

Vous êtes candidats pour le Conseil national ou le Conseil des Etats? Dans ce cas nous souhaitons vous donner la possibilité de vous présenter brièvement dans le Bulletin des médecins suisses. Vous voudrez bien, à cet effet, remplir la formule d'inscription ci-jointe, avec votre photo, et l'envoyer à la rédaction du BMS d'ici le 25 août 2003. Nous avons prié toutes les sociétés cantonales et les sociétés de discipline médicale de remettre cette lettre à leurs consœurs et confrères qui se portent candidats aux prochaines élections parlementaires. Nous allons publier deux fois un appel en ce sens dans le BMS ( $n^{\circ}$ s 32/33 et 34) en espérant qu'ainsi, nous n'oublierons personne.

Les identités des candidats par ordre alphabétique seront publiées dans le BMS $n^{\circ} 36$ du 3 septembre 2003. Nous espérons ainsi offrir un tremplin de choix pour les candidats et de donner à notre lectorat une approche intéressante de la diversité politique du corps médical.

Nous sommes volontiers à votre disposition pour toutes questions et commentaires.

En vous remerciant à l'avance, veuillez agréer, Mesdames, Messieurs, nos meilleures salutation.

Reto Steiner / Markus Trutmann

\begin{tabular}{l} 
Formule \\
Nom, prénoms, titres: \\
\hline Année de naissance: \\
\hline Lieu de résidence/canton: \\
Parti: \\
Titre de spécialiste: \\
Activité professionnelle actuelle / position: \\
Antécédents politiques: \\
L'espace suivant est réservé aux principaux projets politiques qui vous tiennent à cœur \\
(1000 signes au maximum, espaces compris).
\end{tabular}

Veuillez y joindre une photographie en noir/blanc ou en couleurs!

\section{Adresse}

Bulletin des médecins suisses, Steinentorstrasse 13, 4010 Bâle, tél. 0614678551 ou 03135911 50, e-mail: redaktion.saez@emh.ch 